\title{
Pedestrianisation and Parking Policy as a Solution towards Green Transport Plan: A Case Study of Zagreb
}

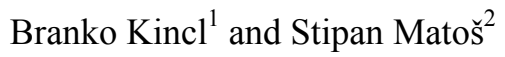 \\ 1. Faculty of Architecture, University of Zagreb, Zagreb 10000, Croatia \\ 2. Department of Transport of Zagreb City, Zagreb 10000, Croatia
}

\begin{abstract}
Strategy of development trends in this moment and at this stage of the traffic comes from understanding the possibilities of the implementation of measures to raise the quality of movement and life in the city. It also includes planning and implementation of targeted interventions in the transport network or facilities. Mobility is a complex process in the area, starting from the departure from the apartment, using various means of transportation, a number of activities in different goals until to return to the location of the apartment. It thus requires extensive transport infrastructure in the form of walkways, bicycle paths, street and railway network. At the same time, reshaping of public transport facilities is needed in which the pedestrian, biker and green concept shall be the main elements of the new spatial conditions. Pedestrian zones development in the city means to create pedestrian areas and green islands in all the places in the city where possible. This process is essential for the transformation of public spaces, in particular, transport corridors. To accomplish the concept of the green transport plan, the need for change in the parking policy is emphasized. This should be an integral part of the city planning and should go hand in hand with the traffic policy.
\end{abstract}

Key words: Strategy of development trends, green transport, pedestrian zones.

\section{Introduction}

Today, moving through the city is manifestation of freedom of each individual's choice and is proportional to the number of possibilities for realization, desires, needs and aspirations in relation to the destination point. Two groups of parallel movement processes in the city are taking place that are seemingly opposite. The first movement is related to the rational selection of the path which is the shortest in time for coming from one point to another (functionality). The second group includes the often unplanned movements or remaining in the interiors of public spaces which reflect the realization of the aspirations of the city inhabitants for a comfortable and pleasant life in the city (emotion). The quality of movement and the presence in the city public areas should be explored and should reflect in the harmonization of these two groups of processes.

Corresponding author: Branko Kincl, emeritus professor, academician, research fields: urbanism and architecture. E-mail: branko@kincl.com.hr.
Urban morphology that occurred throughout history has formed the streets, squares, parks, promenades, coasts, sports and recreation facilities, etc. Therefore, all public or common city areas in which collective life of its inhabitants is carried out. These are the spatial constituent city elements. Architectural forms, such as buildings of all kinds and types are constituent elements of typology $[1,2]$. The content structure that initiates movement in this complex figure creates urban processes of infinite dynamics of people and goods. These intensive and dynamic processes require permanent care for quality improvement of public spaces. The interdisciplinary approach is the basis for working on complex analysis of planning and design of traffic areas in the city [3].

\section{Spatial Traffic Analysis of the Zagreb City}

The results of the traffic study of "The Northern Tangent" (Fig. 1) from 2006 and the traffic study of Zagreb from 2008, which have been included in our 
research, have significantly impacted the development of the city as a whole, and thus the traffic.

Territory, in which the city beneath Zagreb's mountain develops, up to and across the river of Sava, is over $40-\mathrm{km}$ long in the east-west and $3 \sim 5 \mathrm{~km}$ wide in the north-south direction. This elongated territory area of approximately $200 \mathrm{~km}^{2}$ intersects a number of significant longitudinal and transversal routes supplemented with several diagonal routes. Emphasized longitudinality of city development is a logical consequence of its geographical location, layout of the content, population and activities in the area.

In the proposed network, there are two transport routes of central longitudinal speed city roads. Longitudinal directions in the city net are cut by 10 transverse directions and diagonals that typically connect the city areas by bridges on the left and right banks of the city. "The Northern Tangent" (Fig. 1) is planned in the northern perimeter of the city. The southern perimeter of the city already contains a "bypass highway".

Basic transport network is not just supplemented by a series of streets whose primary function is to provide movement of traffic, but also the forming of the built environment in which the street network is an equal part of a complex assembly of public space in which daily life of citizens' is carried out.

\section{Necessity of Planning the Urban Transport}

The prerequisite for the planning of urban transport is knowledge of a large number of parameters and factors, among which the central is the mobility of citizens. It requires extensive transportation infrastructure in the form of hiking, biking, road (street) or the rail networks and parking areas. The construction and expansion of infrastructure leads to a new traffic offer and enables new ways of usage. Planning is a way of attempting to intervene in this complex process by introducing a systematized order with alternative conceptions. Immanent part of the traffic planning system is the conflict that arises from the diverse ways people react to the planned measures. On one hand, planning must try to influence the behavior patterns of people, and on the other hand, planning must adapt to the ways of behavior. Today, we can say that, despite all efforts, we failed to adequately solve the problem of Zagreb and traffic and to achieve the planned goals [4].

\subsection{Conflicts between Transport and Public Space}

Conflicts between transport and public space appear in the planning goals of safety, efficiency and capacity of individual means of transportation and in their relation to each other. Through the surface they need,

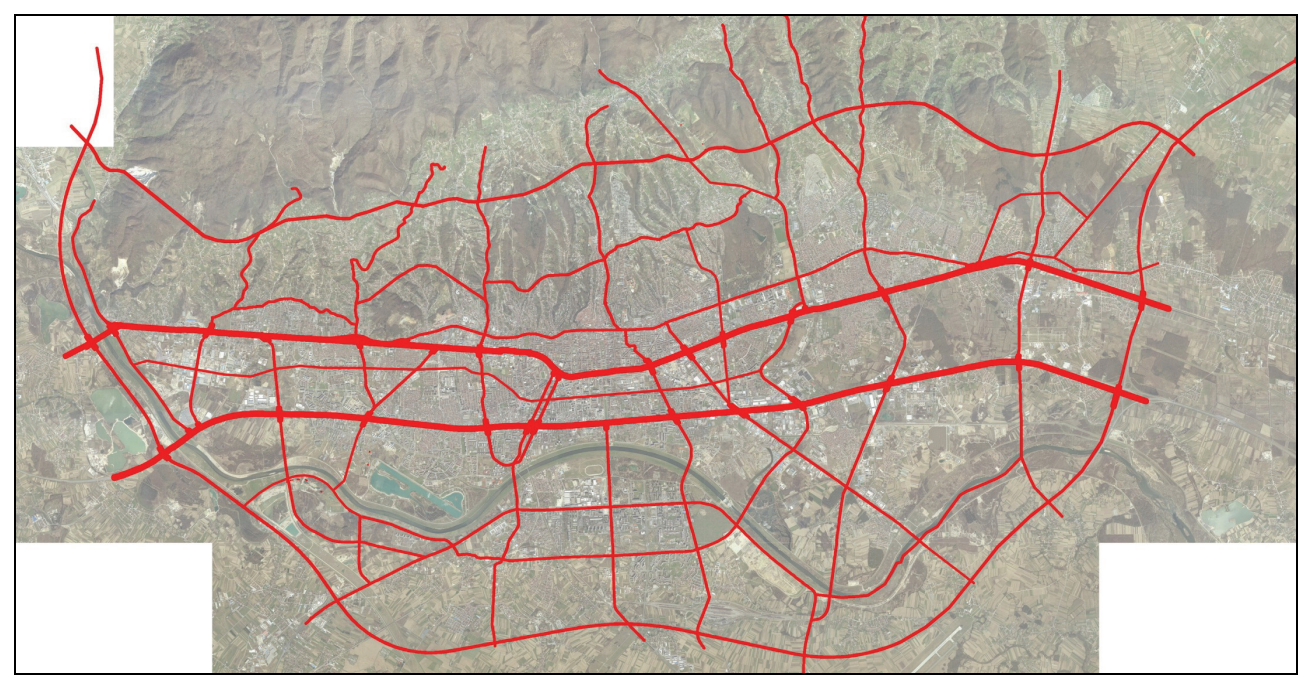

Fig. 1 Schematic overview of the transport network (proposal) [5]. 
they directly change the road space. Width of lanes and their number, extension of nodes, separate paths for pedestrians and cyclists, overpasses and underpasses are in conflict with the available space of roads and squares. But the problem of traffic in the city should not be reduced only to the conflict over the formation of the limited street space. The problem of urban transport planning is an integral and inseparable part of the planning of the urban space.

The main street network in Zagreb's city center is planned and built in the 19th and at the beginning of the 20th century and, by its traffic and technical characteristics, meets today's traffic needs. Through all that time, there was no planning and construction of public parking, which stands out as a major traffic problem today because of the lack of parking spaces. Surface area of the city center (the historic center) is about $2 \%$ of the total area and covers about $10 \%$ of all tertiary activities. Therefore, in the historic center, it is not possible to suspend the traffic but to conduct a selection that would allow access to business entities and flats. Unfortunately, it is in this part that the planners of Zagreb failed even though they were on a good way to solve the practical problem of parking, starting from the Zagreb's DUP (general urban plan) center in 1974 and general transport plan in 1978 [6]. This plan planned to build a garage with total capacity of approximately 25,000 parking spaces. Subsequent amendments to the general urban plan departed from this concept, and the dotted construction of garages was allowed. This was later completely prohibited, while the expansion of pedestrian zones and creation of even bigger problems in the parking of tenants and businesses entities in the central area continued [7].

Today, in the central city area which is covered by the collection of parking, a total of 51,969 cars are registered. If one adds to this approximately 34,000 cars coming to Zagreb daily, there is a need for the subtler managing transport demand and its satisfaction [8].

Construction of garages in the city of Zagreb is particularly delicate issue because of the different approaches of people, professions and investors. Decisions of administrative bodies should be based on existing and new traffic analyzes and studies that provide the possibility of building the so-called block garages, which would partly be used by residents, and partly would be available for public parking. It is necessary to determine the necessary capacity of these garages and construction stages so that the first stage terminates up to $50 \%$ of street parking spaces [9]. This would reduce the "visual pollution" of the city and allow the development of the concept of "developing of the pedestrian zones in the city", i.e., the creation of pedestrian zones and green islands in all the places in the city where possible.

\subsection{Reshaping of Public City Spaces}

The city streets are primary corridors of unhindered movement of people, vehicles and goods, but also of daily events in the urban life of the city. Road space is more than traffic area, it is a place where people are present, and it is the area of communication and perceiving the image of the city. Public city spaces form the urban landscape and contribute to the creation of unique environments that are the key to the experience and memory of the city [10].

Intertwining in the town by green corridors, which is also part of the movement of people network, is a good basis for urban mobility as one of the most important urban processes in the identification of population with the city. Development of an idea about a city includes a development of different types of green areas as a part of a wholesome eco-system (Fig. 2). Categorization of the planned network and detailed standards for equipping and forming the city streets are processed in the traffic study of the city of Zagreb in 2008. Green plan and turning the city of Zagreb in the green pedestrian zones are the most important elements of transformation of street outlines and public spaces. Greenery as a cityscape element significantly changes the physionomy of the city 


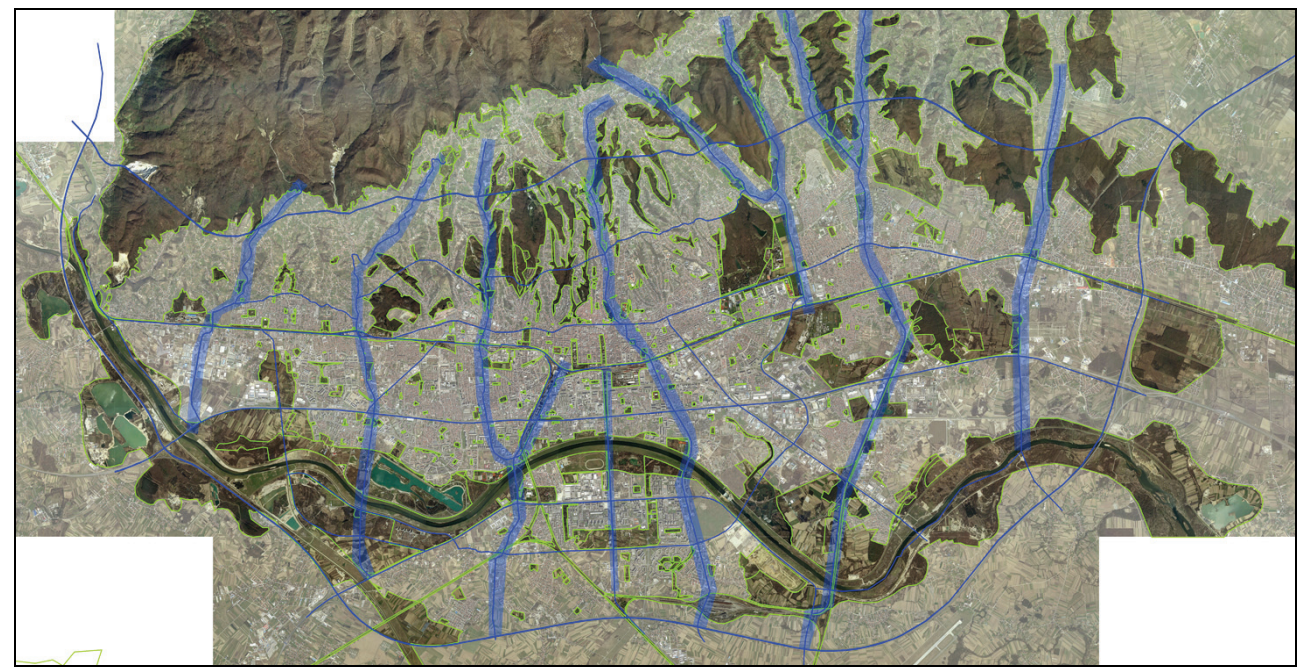

Fig. 2 Green areas of the city (marked in darker shade) and transverse transport corridors [12].

scenery area from which parked cars disappear and dispose within the newly built garage parking space. Green alleys in the historic parts of the city or linear outlines of freely formed groups of greenery in its newer parts are the welfare of the city and its ambientalization [11, 12].

During the historical periods of Zagreb development, extraordinary patterns and greening typology of the series of streets, squares, etc., were created. The need to continue designing public spaces by greenery in contemporary urban development concepts of Zagreb has already been featured in directive regulatory basis in 1949 1953 and in the basic documents of the urban development of the city that followed thereafter [13]. The present time requires significant reshaping of street outlines and other public spaces by greenery which should be weighed following the application of propositions from the categorization proposals of the transport network for the city and the concept of greening and developing the pedestrian zones of the city.

This approach of solving the problem of movement in the modern city a proposal for a new concept of decorating public spaces is created which can be called "green plan and developing of the pedestrian zones of the city". There are a number of zones and street outlines that become pedestrian oasis by simple traffic reorganization.

These pedestrian oases equipped by urban mobiliars, richly planted and connected by walkways and bicycle paths contribute to the quality of life of residents in the city. In this sense, Zagreb has a huge number of still unused opportunities shown by the most basic analysis of the possibilities of forming a system of pedestrian area of the city. Developing the process of making the pedestrian zones of the city is possible to begin at approximately 30 locations that are deployed throughout the metropolitan area on the spacing of $500 \mathrm{~m}$ to $1,000 \mathrm{~m}$. Along with pedestrian movement, the forming of bike route networks is especially suitable in these distances which should connect these exceptional places of leisure time, aesthetic appeal, sociability, identity and environmental awareness of residents of the urban neighborhoods (Figs. 3 and 4). In this regard, the case of the city of Vienna should be noted which, through the process of urban renewal in the last 15 years, realized more than 40 such protected pedestrian zones and islands [14].

\section{Participation of Residents in Decision-Making about the Regulation of the Transport Area}

Implementation of the proposed green transport plan and developing the pedestrian zones of the city as 


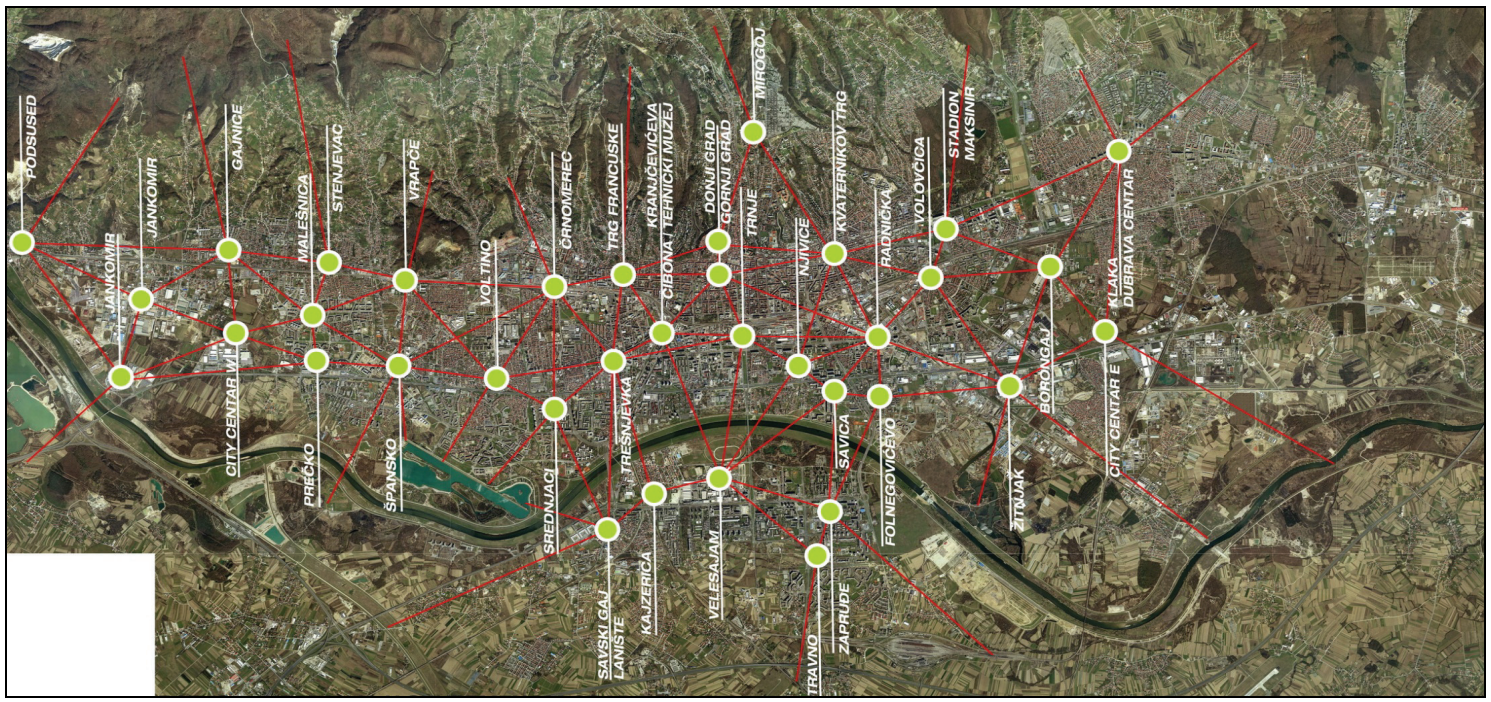

Fig. 3 Schematic overview of the network of possible locations of pedestrian areas.

Note: Dots represent zones of urban sociability-pedestrian areas.

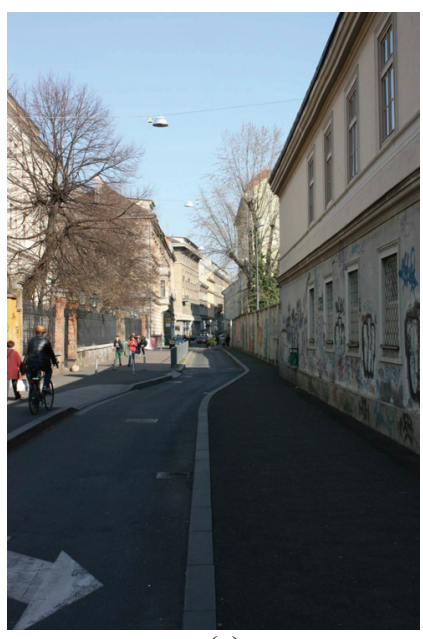

(a)

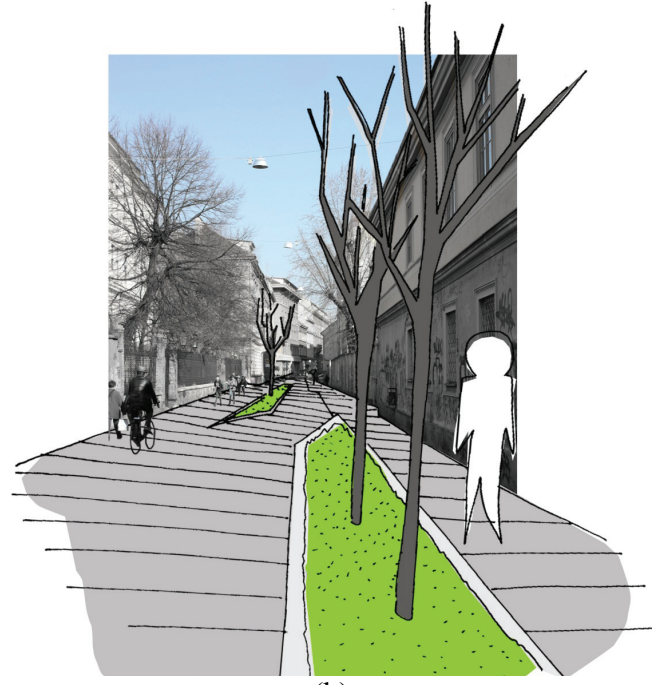

(b)

Fig. 4 Green plan in urban neighborhoods: (a) Varšavska Street; (b) proposal for pedestrian areas.

a socio-cultural intervention of largest urban values shall be, by experience, difficult to implement. It is, therefore, necessary by continuous dialogue through the media, organized forums and specific forms of communication, such as social entrepreneurship as a new paradigm in the approach of solving social problems by engaging as many inhabitants of the city who are final users of the proposed changes $[15,16]$. In particular, it relates to households, companies and institutions that are feeling the effects of the planned measures. In this way, it is possible to form relationships between holders of traffic planning affairs, project contractors and environment in accordance with the objectives of the planned activities, and consequently stimulate the preferred way of environmental conduct by which the conflicts are reduced to the lowest possible level [8].

\section{Conclusions}

The essence of the proposal of the green transport plan and developing pedestrian zones of the city is focused on the creation of the movement organization (traffic) while decorating the town in which the factors of economic, social and environmental 
development shall act on spatial shaping of the idea about the city. At this time, significant and highly valuable urban areas are occupied by parked vehicles. It is believed that the removal of a large number of vehicles from the outstanding parking would be replaced by parking in multi-story parking garage facilities which would release a very large surface area that can transform itself into a pedestrian zone and urban greenery and form a new urban quality and valuable ecological category by equipment. In this way, parking of vehicles would be controlled in a far greater metropolitan area than just the city center. The network of pedestrian areas and greenery of street corridors linked with city parks, forest parks, river banks, meadows and other types of green areas would ensure the city a higher quality of life for its residents.

\section{References}

[1] Rossi, A. 1999. The Architecture of the City. Zagreb: Biblioteka Psefizma.

[2] Kincl, B. 1976. The Center of Zagreb, Detailed Urban Plan. Zagreb: Urban institute of the City of Zagreb.

[3] Elvin, G. 2007. Integrated Practice in Architecture. Hoboken: John Wiley \& Sons, Inc.

[4] Vanderbilt, T. 2011. Driving. Zagreb: Algoritam.

[5] Kincl, B. 2008. Spatial-Traffic Study of Road and Railway System of the Wider Area of Zagreb. Zagerb: IGH and AF, Department of Architecture, Town and Country Planning.

[6] Uhlik, J. 1978. General Traffic Plan of the City of Zagreb.
City Office of Zagreb.

[7] Matoš, S., and Šimurina, S. 2012. "Development of the System of Parking Charging in the City of Zagreb by Changing the Use of Privileged Parking Tickets." Presented at 32nd Conference on Transportation Systems with International Participation, Automation in Transportation 2012, Zagreb, Croatia.

[8] Matoš, S., and Tomšić, D. 2011. "City Traffic Planning and Public Relations." Presented at the Fifth Congress on Croatian Roads, Cavtat, Croatia.

[9] Steierwald, G., and Kunne, H. D. 1994. City Transport Planning, Part A. Berlin Heidelberg: Springer-Verlag. (in German)

[10] Cerasi, M. 1976. City Collective Spaces. Milano: Gabriele Mazzotta Editore. (in Italian)

[11] Kincl, B. 2013. "The Art of Breathing and Design of the City in Zagreb Example." Presented at International Scientific Conference "Greenery of Zagreb", Zagreb, Croatia.

[12] Jacobs, B. A. 1993. Great Streets. Cambridge: MIT (Massachusetts Institute of Technology).

[13] Ivanković, V. 2013. "Concept of Green Zagreb in the Vision of the Architect Vladimir Antolić." Presented at International Scientific Conference "Greenery of Zagreb", Zagreb, Croatia.

[14] Pasteiner, H. J. 2003. Urban-Space-Experience/Design for Public Space in Vienna/Vienna Urban Development and Planning. Vienna: Municipal Administration of the city of Vienna.

[15] Bežovan, G. 2005. Civil Society. Zagreb: Publishing House Globus.

[16] Dakić, S. 2008. "Strategic Issues and Challenges of the Development of Zagreb." Presented at Conference Development of Zagreb, Zagreb, Croatia. 